\begin{tabular}{|c|c|}
\hline Title & A ngular and velocity distributions of desorbing product carbon dioxide from two reaction sites on platinum(110)(1× 2$)$ \\
\hline Author(s) & Ohno, Y uichi; Matsushima, Tatsuo; Uetsuka, Hiroshi \\
\hline Citation & $\begin{array}{l}\text { The Journal of Chemical Physics, 101(6), 5319-5328 } \\
\text { https://doi.org/10.1063/1.467386 }\end{array}$ \\
\hline Issue Date & 1994-09-15 \\
\hline Doc URL & http:/hdl.handle.net/2115/11327 \\
\hline Rights & Copyright (c) 1994 A merican Institute of Physics \\
\hline Type & article \\
\hline File Information & 7650222_Pt110_1x2_CO_oxidation_1994.pdf \\
\hline
\end{tabular}

Instructions for use 


\title{
Angular and velocity distributions of desorbing product carbon dioxide from two reaction sites on platinum(110)(1×2)
}

\author{
Yuichi Ohno and Tatsuo Matsushima ${ }^{\text {a) }}$ \\ Catalysis Research Center, Hokkaido University, Sapporo 060, Japan \\ Hiroshi Uetsuka \\ Institute of Materials Science, The University of Tsukuba, Ibaraki 305, Japan
}

(Received 26 January 1994; accepted 6 June 1994)

\begin{abstract}
The angular and velocity distributions of desorbing product $\mathrm{CO}_{2}$ were studied on a platinum $(110)(1 \times 2)$ surface over a wide range of $\mathrm{CO}$ coverages by means of angle-resolved thermal desorption combined with a cross-correlation time-of-flight (TOF) technique. Heating the coadsorption layer of $\mathrm{CO}$ and oxygen yields four $\mathrm{CO}_{2}$ formation peaks $\mathrm{P}_{1}-\mathrm{CO}_{2}(\sim 400 \mathrm{~K}), \mathrm{P}_{2}-\mathrm{CO}_{2}$ $(300 \mathrm{~K}), \mathrm{P}_{3}-\mathrm{CO}_{2}(250 \mathrm{~K})$, and $\left.\mathrm{P}_{4}-\mathrm{CO}_{2}(170 \mathrm{~K})\right]$. The angular distribution of each $\mathrm{CO}_{2}$ produced at high $\mathrm{CO}$ coverages consists of three desorption components. Two of them show desorption collimated along the inclined terrace normal; the other shows it along the bulk surface normal. The former is assigned to reaction on the inclined terrace, and the latter mostly to reaction on the bottom of the trough. The translational temperature of each desorption component is derived by deconvoluting the TOF spectrum. This temperature reaches $1000-1500 \mathrm{~K}$. The maximum translational temperature is always observed in the normal direction of each reaction site. For $\mathrm{P}_{2}$-and $\mathrm{P}_{3}-\mathrm{CO}_{2}$, the maximum translational temperature of the normal-directional component is lower than that of the inclined components. For $\mathrm{P}_{4}-\mathrm{CO}_{2}$, on the other hand, the maximum translational temperature of the normal-directional component is close to that of the inclined components. A transfer mechanism of reaction sites is proposed.
\end{abstract}

\section{INTRODUCTION}

The spatial distribution of desorbing product molecules gives structural information on reaction sites when they are repulsively desorbed. ${ }^{1,2}$ Their velocity distribution should be more sensitive to the structure since it brings directly dynamic information of the reaction, whereas the flux distribution is essentially determined by the ratio of normal velocity component to that parallel to the surface plane. ${ }^{3}$ A significant anisotropy is found in both distributions of desorbing product $\mathrm{CO}_{2}$ over $\mathrm{Pd}(110)$. It can be explained by a simple consideration of the local geometry of the reaction site. The orientation of the reaction site is also preserved in these distributions, as confirmed on reconstructed $\operatorname{Pt}(110)(1 \times 2)$, ${ }^{4,5}$ $\operatorname{Ir}(110)(1 \times 2){ }^{6}$ and stepped $\mathrm{Pt}(112){ }^{7}$ These distributions also depend on the density of reactants around reaction sites. ${ }^{1-3}$

The surface of $\mathrm{Pt}(110)$ displays a stable $(1 \times 2)$ reconstruction after high-temperature annealing. This structure is explained by a "missing row model," in which every second atomic row in the $[110]$ azimuth is missing. ${ }^{8-11}$ There are three-atom-wide terraces of a (111) structure, which incline about $\pm 30^{\circ}$ in the [001] direction. The structure is stable even when the surface is covered by a small amount of $\mathrm{CO}$. We reported previously the spatial and velocity distributions of reactive $\mathrm{CO}_{2}$ desorption on such reconstructed surfaces. The desorption is sharply collimated along the terrace surface normal, at about $\pm 25^{\circ}$ in the [001] direction. This indicates that the reactive desorption takes place on the narrow terraces. ${ }^{4}$ Velocity distribution measurements confirm this conclusion. The translational temperature of $\mathrm{CO}_{2}$ is much

'To whom all correspondence should be sent. higher than the surface temperature and is maximized around the terrace surface normal.

No two-directional desorption, however, is found in the $\mathrm{CO}_{2}$ distribution at high $\mathrm{CO}$ coverages on this surface. ${ }^{4}$ The desorption shows a single peak in angular distribution in the [001] direction, which is collimated along the bulk surface normal. The reaction also occurs on sites parallel to the bulk surface plane. The reconstruction is partly lifted during heating procedures, as confirmed by scanning-tunneling microscopy $(\mathrm{STM})^{9}$ and low-energy electron diffraction (LEED) observations. ${ }^{4,12}$ No detailed measurements, however, have been reported for angular and velocity distributions on the surface of such mixed structures.

In this paper, we examine both distributions of desorbing product $\mathrm{CO}_{2}$ over a wide range of $\mathrm{CO}$ coverages. The distributions were measured as a function of desorption angle in the [001] direction and were deconvoluted into three components. Two of the components show desorption collimated along the inclined terrace normal, and the other along the bulk surface normal. They are produced on different reaction sites. Time-of-flight (TOF) curves are also deconvoluted into three components. The translational temperature of each component is much higher than the surface temperature, indicating that the reactive $\mathrm{CO}_{2}$ desorption is strongly repulsive. It depends on the structure of the reaction sites.

\section{EXPERIMENTAL METHOD}

The experimental apparatus and procedures were reported previously. ${ }^{3}$ The apparatus consists of three chambers pumped separately. A reaction chamber has LEED-Auger electron spectroscopy (AES) optics, an $\mathrm{Ar}^{+}$gun, and a mass spectrometer. A sample crystal in a disk-shaped slice $(12 \mathrm{~mm}$ 
in diameter $\times 0.9 \mathrm{~mm}$ thick) is set on top of an L-shaped manipulator. The crystal can be rotated at the top to change the desorption angle ( $\theta$ is the polar angle). A chopper chamber has a slit on each end. The distance between the chopper blade and the ionizer of the mass spectrometer in the analyzer chamber is $304 \mathrm{~mm}$. The acceptance angle of the aperture of the ionizer is $2.1^{\circ} \times 1.1^{\circ}$. The angular resolution and signal treatments are improved, compared to the previous measurements. ${ }^{4}$

The sample surface was prepared as follows: repeated $\mathrm{Ar}^{+}$bombardment in the temperature range of $300-1000 \mathrm{~K}$ and heating in $5 \times 10^{-8}$ Torr oxygen at $800 \mathrm{~K}$ achieved a clean $(1 \times 2)$ structure. In each adsorption-desorption cycle, the sample was annealed to $1100 \mathrm{~K}$ for a moment in order to rcmove metastable $(1 \times 1)$ domains. ${ }^{13,14}$

In angle-resolved thermal desorption spectroscopy (TDS) experiments, the clean and well-ordered surface is exposed to ${ }^{18} \mathrm{O}_{2}$ and ${ }^{12} \mathrm{C}^{16} \mathrm{O}$ sequentially at low temperatures and heated resistively at a constant rate. The desorption of product ${ }^{12} \mathrm{C}^{16} \mathrm{O}^{18} \mathrm{O}$ is monitored in angle-integrated form by the mass spectrometer in the reaction chamber and also in angle-resolved form by the other mass spectrometer in the analyzer chamber. The ratio of the peak height in both forms is plotted against the desorption angle after it is multiplied by the factor of $\cos \theta$, since an increasing area of the surface falls into the aperture of the collimator as the desorption angle increases. ${ }^{18} \mathrm{O}$ will be simply referred to as $\mathrm{O}$ hereafter since only ${ }^{12} \mathrm{C}^{16} \mathrm{O}^{18} \mathrm{O}$ is produced during the above procedures.

For TOF measurements, the flow of $\mathrm{CO}_{2}$ passing through the first slit is modulated by a pseudorandom chopper. ${ }^{15} \mathrm{CO}_{2}$ is ionized after it passes through the second slit and is detected. A time resolution of $15 \mu \mathrm{s}$ was selected for the experiments. TDS procedures were repeated 100-300 times to achieve a tolerable TOF spectrum.

\section{RESULTS}

\section{A. Reactant adsorption}

The adsorption, as well as the coadsorption, of $\mathrm{CO}$ and oxygen on the present surface has been previously reported. ${ }^{4}$ Their coverages $\theta_{C O}$ and $\theta_{O}$ were determined by thermal desorption and normalized to the values in the literature. The density of $\mathrm{CO}$ is $0.92 \times 10^{15} / \mathrm{cm}^{2}$ at saturation, where a $c(8$ $\times 4)$ structure is formed. ${ }^{12,16}$ This is equal to the density of topmost metal atoms on $\mathrm{Pt}(110)(1 \times 1)$. CO is desorbed at temperatures higher than those for $\mathrm{CO}_{2}$ formation. The adsorption of $\mathrm{CO}$ in large amounts causes a removal of $(1 \times 2)$ reconstruction above room temperature. ${ }^{9}$ The removal is slow at temperatures below $240 \mathrm{~K}$ because of the restricted surface diffusivity of platinum atoms. ${ }^{12}$

Oxygen adsorbs molecularly $\sim 150 \mathrm{~K}$. The desorption and dissociation of the resultant admolecules are complete below $250 \mathrm{~K}^{17}$ The density of oxygen adatoms is $0.32 \times 10^{15}$ atoms $/ \mathrm{cm}^{2}$ when they are produced with large exposures above $250 \mathrm{~K}{ }^{18}$ The coverage is defined as the ratio of the number of oxygen adatoms to that of topmost metal atoms on $\operatorname{Pt}(110)(1 \times 1)$. Thus, this saturation cover is 0.35 . The reconstruction is not removed by adsorption of molecular

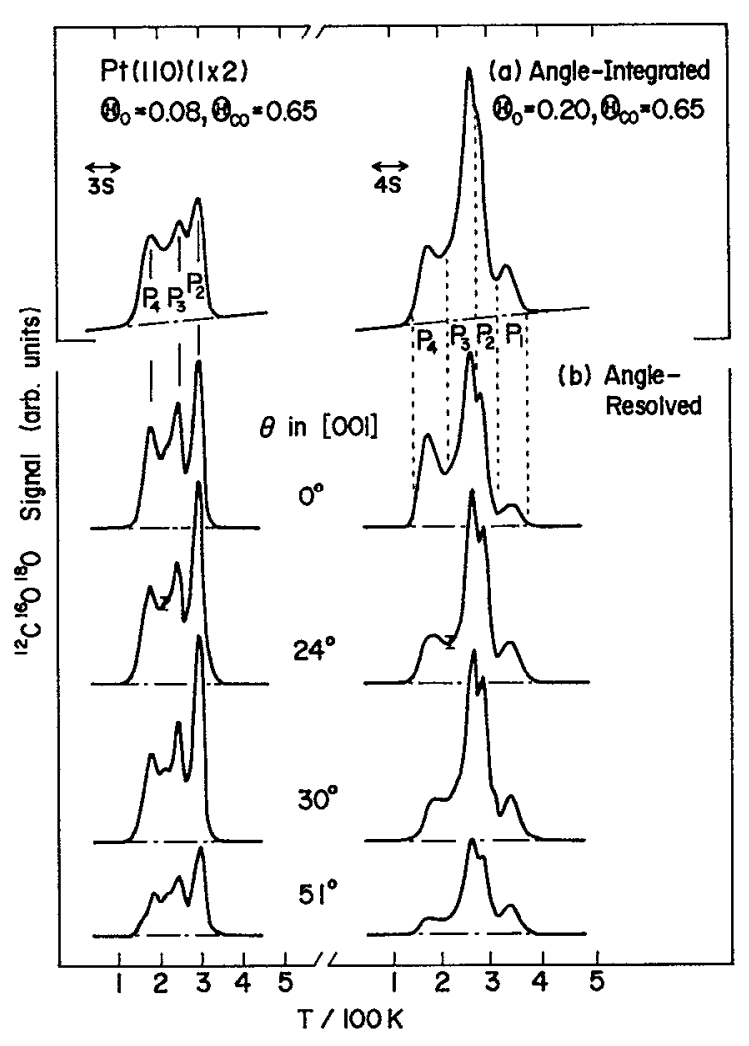

FIG. 1. (a) $\mathrm{CO}_{2}$ desorption spectra in angle-integrated form at a high $\mathrm{CO}$ coverage, and (b) angle-resolved spectra observed at various desorption angles in the [001] direction. The left panel represents typical spectra used for angular distribution measurements. The right panel summarizes some spectra used for velocity distribution measurements. The dashed lines indicate the temperatures at which the signal accumulation was switched into another channel. The heating rate was $17 \mathrm{~K} / \mathrm{s}$.

oxygen as well as atomic form. ${ }^{18}$ The $\mathrm{CO}$ coverage on the oxygen-covered surface is determined from a $\mathrm{CO}$ exposure curve on the clean surface, since the $\mathrm{CO}$ adsorption is not retarded by the presence of oxygen adatoms. Preadsorbed oxygen is partly removed as $\mathrm{CO}_{2}$ during exposure to large amounts of $\mathrm{CO}$ since the $\mathrm{CO}$ adsorption temperature of 150 $\mathrm{K}$ is not low enough to quench the reaction at high coverages. Therefore, both coverages are somewhat overestimated at high $\mathrm{CO}$ exposures.

\section{B. $\mathrm{CO}_{2}$ formation}

Typical $\mathrm{CO}_{2}$ desorption spectra are shown in Fig. 1. The upper panel shows spectra in angle-integrated form, and the lower shows spectra in angle-resolved form at various desorption angles in the [001] direction. The inserted coverages represent the initial values before the subsequent heating procedures. The formation of $\mathrm{P}_{1}-\mathrm{CO}_{2}$ is observed $\sim 400 \mathrm{~K}$ only when the total coverage is small. As the $\mathrm{CO}$ coverage increases, the $\mathrm{CO}_{2}$ formation is extended to lower temperatures, yielding three additional peaks $\mathrm{P}_{2}-\mathrm{CO}_{2}$ at $300 \mathrm{~K}$, $\mathrm{P}_{3}-\mathrm{CO}_{2}$ at $250 \mathrm{~K}$, and $\mathrm{P}_{4}-\mathrm{CO}_{2}$ at $170 \mathrm{~K}$. The $\mathrm{P}_{2}-\mathrm{CO}_{2}$ peak appears over extended $\mathrm{CO}$ coverages, whereas the $\mathrm{P}_{3}-\mathrm{CO}_{2}$ and $\mathrm{P}_{4}-\mathrm{CO}_{2}$ peaks are predominant at $\mathrm{CO}$ coverages higher than 0.5 . The left-hand side of the panel represents spectra 

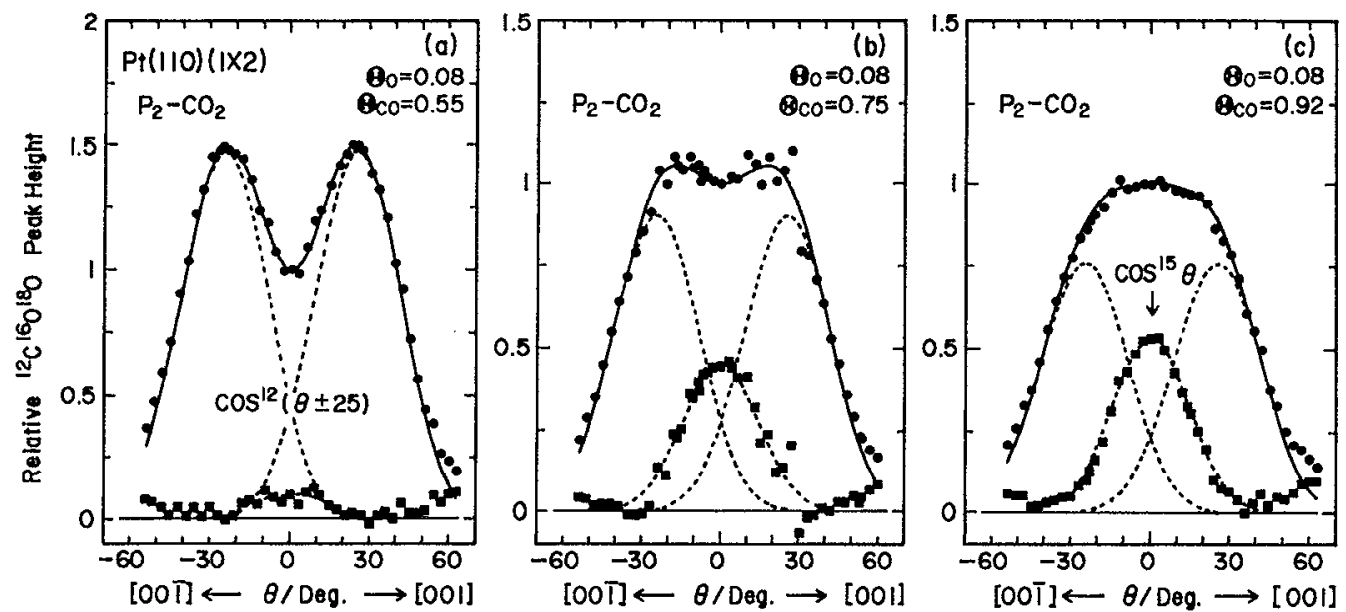

FIG. 2. Angular distribution of $\mathrm{P}_{2}-\mathrm{CO}_{2}$ in the [001] direction. The thermal desorption is started at $\theta_{\mathrm{O}}=0.08$ and at (a) $\theta_{\mathrm{co}}=0.55$; (b) 0.75 ; and (c) 0.92 . The circles represent the $\mathrm{CO}_{2}$ signal determined experimentally. The squares indicate the difference between the experimental signal and the two-directional desorption represented by the dashed lines. The solid curves represent the summation of the three components.

when a clean and well-ordered reconstructed surface is exposed to $\mathrm{O}_{2}$ at $250 \mathrm{~K}$, and further to $\mathrm{CO}$ at $150 \mathrm{~K}$. This preparation was used for angular distribution measurements. It yields three well-resolved $\mathrm{CO}_{2}$ peaks.

The right-hand side summarizes $\mathrm{CO}_{2}$ spectra when the surface is exposed to $\mathrm{O}_{2}$ at $150 \mathrm{~K}$, followed by annealing up to $230 \mathrm{~K}$, and further exposure to $\mathrm{CO}$ at $150 \mathrm{~K}$. This procedure yields four $\mathrm{CO}_{2}$ formation peaks and relatively high signal count rates, although the separation of $\mathrm{P}_{2}-\mathrm{CO}_{2}$ from $\mathrm{P}_{3}-\mathrm{CO}_{2}$ is poor. The procedure was used for velocitydistribution measurements. Noticeable differences in both spectra are caused by the difference in the oxygen coverage. However, no dependence on the oxygen coverage of angular distribution of each $\mathrm{CO}_{2}$ peak was previously reported. ${ }^{4}$

Significant differences were found between these spectra and those reported previously. ${ }^{4}$ These are caused by the higher temperature of $150 \mathrm{~K}$ for $\mathrm{CO}$ exposure. $\mathrm{P}_{4}-\mathrm{CO}_{2}$ formation has already started during $\mathrm{CO}$ exposures at this temperature. This is why the $\mathrm{P}_{4}-\mathrm{CO}_{2}$ peak is not highly enhanced as compared with the previous measurements.

\section{Angular distribution}

The angular distribution of $\mathrm{P}_{1}-\mathrm{CO}_{2}$ observed at $\theta_{\text {Co }}<0.1$ shows a two-directional desorption collimated at either $+23^{\circ}$ or $-23^{\circ}$ off the bulk surface normal in the [001] direction, as reported previously. ${ }^{4,5}$ The distribution of each component has a $\cos ^{12}(\theta \pm 23)$ dependence. The reactive desorption takes place on inclined terraces of reconstructed (1 $\times 2) . \mathrm{P}_{2}-\mathrm{CO}_{2}$ is produced above $\theta_{\mathrm{CO}}=0.1$. Its angular distribution indicates a similar two-directional desorption collimated at either $+25^{\circ}$ or $-25^{\circ}$ off the bulk surface normal at $\theta_{\mathrm{CO}}<$ about 0.5 . With increasing $\mathrm{CO}$ coverage, the two-directional desorption coalesces into a broad single peak collimated along the bulk surface normal. These features are shown in Fig. 2.

$\mathrm{P}_{3}-\mathrm{CO}_{2}$ is formed above $\Theta_{\mathrm{CO}}=0.5$. The desorption exhibits a clear two-directional distribution at $0.5<\theta_{\mathrm{CO}}<0.6$ as shown in Fig. 3(a). This desorption is collimated at $+25^{\circ}$ and $-25^{\circ}$ off the bulk surface normal, similar to the collimation of $\mathrm{P}_{2}-\mathrm{CO}_{2}$. When the $\mathrm{CO}$ coverage exceeds about 0.6 , the distribution again coalesces into a single peak as shown in Fig. 3(b). The distribution is sharply collimated along the bulk surface normal as $\cos ^{3} \theta$ at $\theta_{\mathrm{CO}}=0.92$ [Fig. 3(c)]. The formation of $\mathrm{P}_{4}-\mathrm{CO}_{2}$ is observed above $\theta_{\mathrm{CO}}=0.6$. The angular distribution is shown in Fig. 4. No two-directional desorption is apparent. The desorption is always collimated along the bulk surface normal. The angular distribution becomes sharper with increasing $\mathrm{CO}$ coverages. It has a $\cos ^{3.5} \theta$ dependence at $\theta_{\mathrm{CO}}=0.92$. These distributions are in general agreement with the previous measurements, which were performed at a somewhat lower resolution of the desorption angle. ${ }^{4}$

These sequences of the angular distributions can be explained reasonably by the superposition of two-directional and normal-directional desorption. Now we introduce a procedure to deconvolute the distribution curve into three components. The distribution of each component in twodirectional desorption is assumed to have a $\cos ^{12}(\theta \pm 25)$ form in the [001] direction. The fraction of this component is determined in such a way that their distribution curves fit with the experimental data at desorption angles higher (or lower) than about $30^{\circ}$ (or $-30^{\circ}$ ). The normal-directional component is derived as the difference between the observed signal and the intensity calculated from the two-directional desorption curves. The resultant distribution is sharply collimated along the bulk surface normal and has $a \cos ^{15} \theta$ form in common among $\mathrm{P}_{2}-\mathrm{CO}_{2}, \mathrm{P}_{3}-\mathrm{CO}_{2}$, and $\mathrm{P}_{4}-\mathrm{CO}_{2}$.

As illustrated in Figs. 2-4, the deconvolution works well for the angular distributions of $\mathrm{P}_{2}-\mathrm{CO}_{2}, \mathrm{P}_{3}-\mathrm{CO}_{2}$, and $\mathrm{P}_{4}-\mathrm{CO}_{2}$ at different $\mathrm{CO}$ coverages. No $\mathrm{CO}$ coverage dependence was found in the angular distribution of the normaldirectional component. Only the fraction increases with increasing $\mathrm{CO}$ coverage. The normal-directional component shows an anisotropy in the angular distribution quite similar 

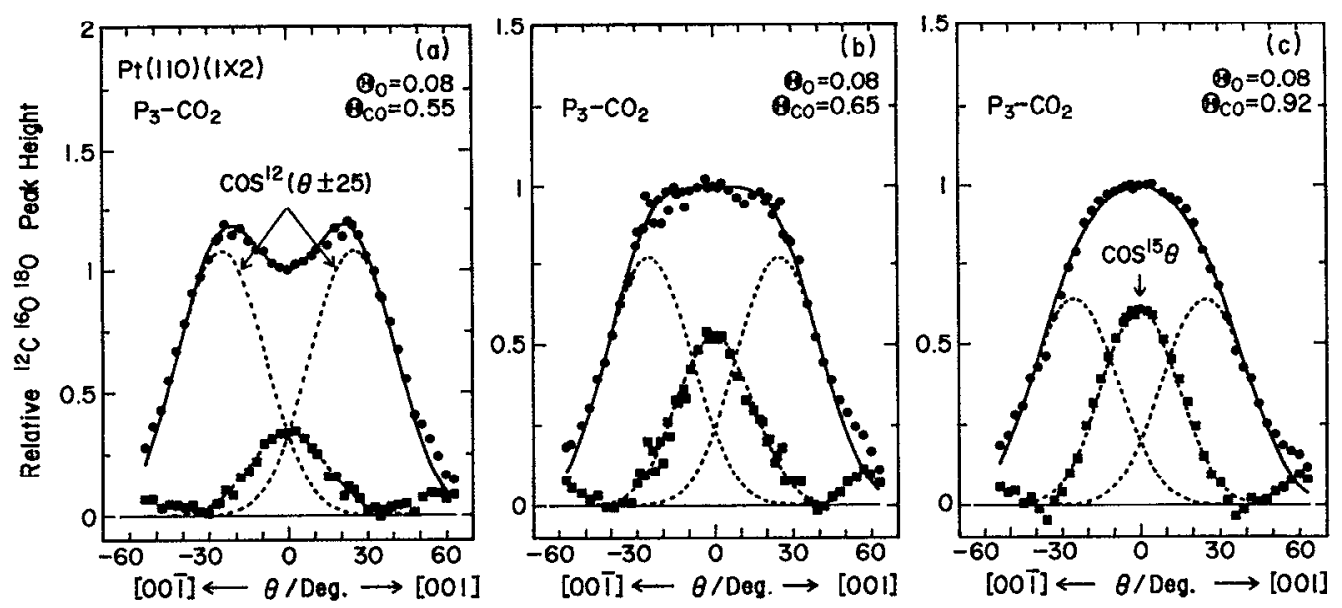

FIG. 3. Angular distribution of $\mathrm{P}_{3}-\mathrm{CO}_{2}$ in the [001] direction. The heating procedure is started at $\Theta_{\mathrm{O}}=0.08$ and at (a) $\Theta_{\mathrm{CO}}=0.55$; (b) 0.65 ; and (c) 0.92 . The other notations are given in Fig. 2.

to that on $\operatorname{Pd}(110),{ }^{2,3}$ It contributes mostly to the signal around the surface normal at high $\mathrm{CO}$ coverages. The fraction is increased in the order of $\mathrm{P}_{4}-\mathrm{CO}_{2}>\mathrm{P}_{3}-\mathrm{CO}_{2}>\mathrm{P}_{2}-\mathrm{CO}_{2}$. It is always intense in $\mathrm{P}_{4}-\mathrm{CO}_{2}$, although at high CO coverages, the two-directional component still remains.

\section{Velocity distribution}

The signal in TOF measurements is accumulated separately for each $\mathrm{CO}_{2}$ peak. Four channels of a multichannel scaler were sequentially used in the following temperature ranges: $150-230 \mathrm{~K}$ for $\mathrm{P}_{4}-\mathrm{CO}_{2}, 230-280 \mathrm{~K}$ for $\mathrm{P}_{3}-\mathrm{CO}_{2}$, $280-320 \mathrm{~K}$ for $\mathrm{P}_{2}-\mathrm{CO}_{2}$, and $320-380 \mathrm{~K}$ for $\mathrm{P}_{1}-\mathrm{CO}_{2}$. The dotted lines in the right panel of Fig. 1 indicate these temperatures. Typical TOF spectra of $\mathrm{P}_{2}-\mathrm{CO}_{2}, \mathrm{P}_{3}-\mathrm{CO}_{2}$, and $\mathrm{P}_{4}-\mathrm{CO}_{2}$ at a medium $\mathrm{CO}$ coverage are shown in Figs. 5, 6, and 7 , respectively. The signal-to-noise ratio falls below our level of tolerance at desorption angles higher (or lower) than $\sim 45^{\circ}$ (or $-45^{\circ}$ ).
The origin of the abscissa is shifted $40 \mu \mathrm{s}$ due to the ion drift time of ${ }^{12} \mathrm{C}^{16} \mathrm{O}^{18} \mathrm{O}^{+}$in the mass spectrometer. With a flight path of $304 \mathrm{~mm}$, the maximum signal intensity of $\mathrm{P}_{2}-\mathrm{CO}_{2}$ appears at 335,305 , and $325 \mu$ s at $\theta=0^{\circ}, 24^{\circ}$, and $48^{\circ}$ in the [001] azimuth. As illustrated in Fig. 5(a), these are shifted to a great extent from the peak position of $650 \mu \mathrm{s}$, which is expected in the Maxwellian distribution at the surface temperature of $\mathrm{P}_{2}-\mathrm{CO}_{2}$ desorption $(300 \mathrm{~K})$. Similar features are also observed in the TOF spectra of $\mathrm{P}_{3}-\mathrm{CO}_{2}$ and $\mathrm{P}_{4}-\mathrm{CO}_{2}$. Most of the product molecules desorb with velocities higher than those expected from the equilibrium velocity distribution at the surface temperature. This means that a strong repulsive interaction operates in the reactive $\mathrm{CO}_{2}$ desorption.

The mean translational energy $\langle E\rangle$ and the normalized speed ratio $\mathrm{SR} \equiv\left(\left\langle v^{2}\right\rangle /\langle v\rangle^{2}-1\right)^{1 / 2} /(32 / 9 \pi-1)^{1 / 2}$ can be derived numerically from observed velocity distributions without assumption on a functional form of the spectra. ${ }^{19} v$ is the
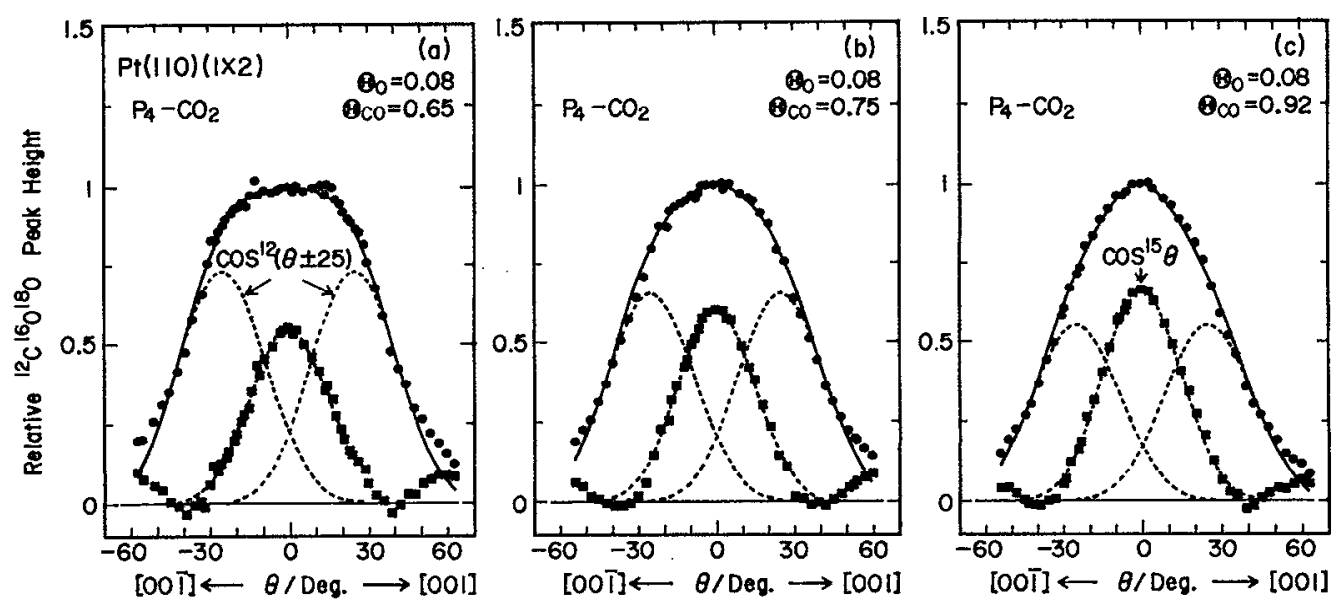

FIG. 4. Angular distribution of $\mathrm{P}_{4}-\mathrm{CO}_{2}$ in the [001] direction. The thermal desorption is started at $\Theta_{\mathrm{O}}=0.08$ and at (a) $\Theta_{\mathrm{CO}}=0.65$; (b) 0.75 ; and (c) 0.92 . The other notations are given in Fig. 2. 


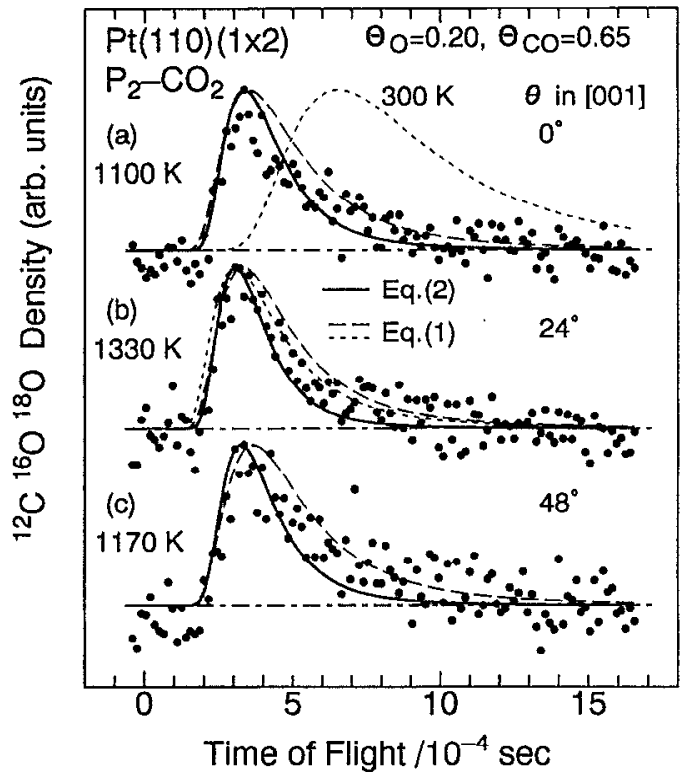

FIG. 5. TOF spectra of $\mathrm{P}_{2}-\mathrm{CO}_{2}$ desorbing in the normal and off-normal directions in the [001] azimuth. The experimental spectra indicated by black circles are shifted by the ion drift time of $40 \mu \mathrm{s}$. The solid curves represent the distributions of Eq. (2) with parameters obtained from the curve fit. The values of $T_{\langle E\rangle}$ calculated from this method are inserted. The dashed curves represent the Maxwellian distribution at $T=T_{\langle E\rangle}$, where $T_{\langle E\rangle}$ is obtained from the numerical treatment of the experimental TOF data. The dotted curves in (a) and (b) are Maxwellian distributions at 300 and $1370 \mathrm{~K}$, respectively. The gate time is $15 \mu \mathrm{s}$ and the flight path is $304 \mathrm{~mm}$.

velocity of the molecule, $\langle v\rangle$ is the mean velocity, and $\left\langle v^{2}\right\rangle$ is the mean square velocity. The translational temperature $T_{\langle E\rangle}=\langle E\rangle / 2 k$ is usually used to represent the mean translational energy in temperature units, while SR measures the

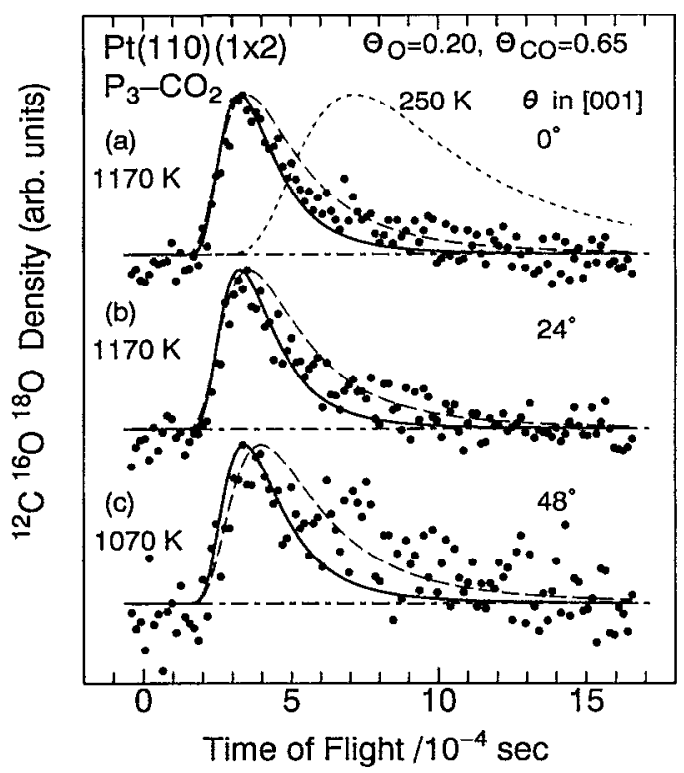

FIG. 6. TOF spectra of desorbing $\mathrm{P}_{3}-\mathrm{CO}_{2}$ at three desorption angles in the [001] direction. The solid and dashed curves represent the distributions obtained from methods deseribed in Fig. 5.

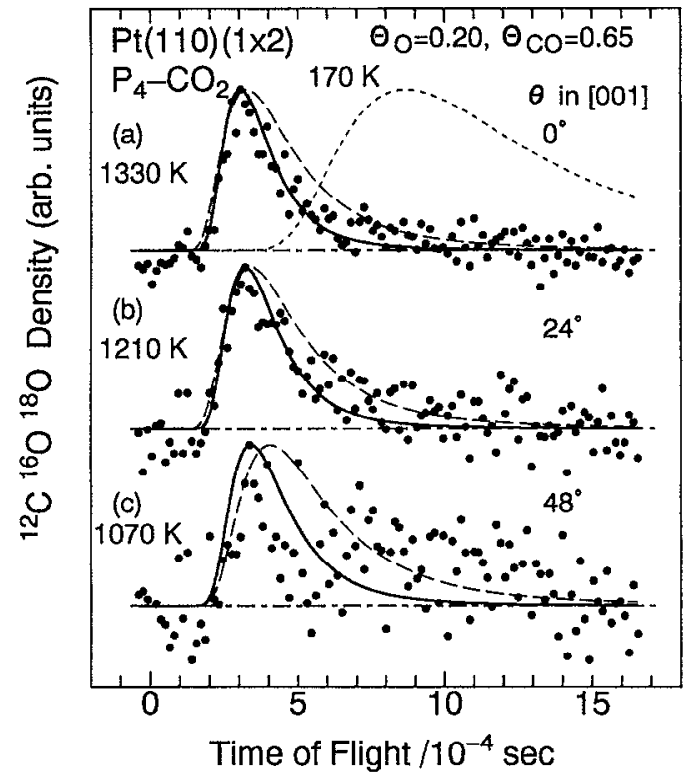

FIG. 7. TOF spectra of desorbing $\mathrm{P}_{4}-\mathrm{CO}_{2}$ at three desorption angles in the [001] direction. The solid and dashed curves represent the distributions obtained from the methods described in Fig. 5.

width of TOF spectra. $k$ is the Boltzmann constant. The spectrum of $\mathrm{P}_{2}-\mathrm{CO}_{2}$ at $\theta=24^{\circ}$ results in $T_{\langle E\rangle}=1170 \mathrm{~K}$ and SR $=0.77$. $T_{\langle E\rangle}$ amounts to about four times the surface temperature. SR is about $20 \%$ less than that of the Maxwellian distribution.

Simple functional forms are examined for the velocity distribution in order to find the best-fit curve for the experimental TOF spectra. One is the Maxwellian velocity distribution

$$
n(v)=N v^{4} \exp \left(-m v^{2} / 2 k T\right),
$$

where $m$ is the mass of the molecule and $N$ is the normalization factor. It should be noted that the signal intensity of TOF spectra $n(v)$ represents the instantaneous density of molecules. A TOF curve is determined uniquely from the position of the maximum signal intensity in the observed TOF spectrum, since only an adjustable parameter $T$ is involved in Eq. (1). This procedure (peak fit) was carried out in the previous work. ${ }^{3,5,20}$ A typical TOF curve calculated in this way is shown by the dotted curve in Fig. 5(b). The observed signal level, however, goes below the calculated curve when the peak height is normalized to its maximum intensity. The actual peak width is narrower than that in the Maxwellian distribution, as indicated by the value of SR. Such a narrow distribution often is found in the reactive desorption surmounting a high activation barrier. ${ }^{21}$ Moreover, $T_{\langle E\rangle}$ derived from the peak fit with Eq. (1) is $1370 \mathrm{~K}$, which is $200 \mathrm{~K}$ higher than that obtained from the numerical treatment of the experimental TOF data. This discrepancy arises mainly from the functional form of the TOF curve in the range of shorter flight time.

The other fit function can reduce these deficiencies significantly. It has the following form: ${ }^{22}$ 


$$
n(v)=N v^{4} \exp \left[-\left(v-v_{0}\right)^{2} / \alpha^{2}\right]
$$

This equation includes two parameters $v_{0}$ and $\alpha$. The peak width of the distribution is determined primarily by $\alpha$. The position of the TOF peak depends on both $v_{0}$ and $\alpha$. We can obtain a close agreement between the observed TOF peak profile and the calculated curve with the best choice of these parameters. For the spectrum of $\mathrm{P}_{2}-\mathrm{CO}_{2}$ at $\theta=24^{\circ}$ in Fig. 5 (b), this method (curve fit) yields $T_{\langle E\rangle}=1330 \mathrm{~K}$ and SR $=0.75$ with the use of $v_{0}=6.34 \times 10^{4} \mathrm{~cm} / \mathrm{s}$ and $\alpha=4.25 \times 10^{4}$ $\mathrm{cm} / \mathrm{s}$. The resultant TOF profile is shown by the solid curve designated as Eq. (2) in Fig. 5(b). It shows a better agreement with the observed TOF spectrum. This $\alpha$ value yields the TOF peak width that is expected in the Maxwellian distribution at only $500 \mathrm{~K}$. As illustrated in Figs. 5(a) $-5(\mathrm{c})$, the observed TOF spectra at various desorption angles can be described approximately by this fit function with the use of a constant $\alpha$ value and an adjustable $v_{0}$ value. It should be noted that the distribution in the range of longer flight time tends to be underestimated. This leads somewhat to an overestimation of $T_{\langle E\rangle}$ and to an underestimation of SR. The TOF data for $\mathrm{P}_{3}-\mathrm{CO}_{2}$ and $\mathrm{P}_{4}-\mathrm{CO}_{2}$ were analyzed in a similar way. These results are displayed by the solid curves in Figs. 6 and 7.

$T_{\langle E\rangle}$ and $\mathrm{SR}$ for $\mathrm{P}_{2}-\mathrm{CO}_{2}$ were calculated as a function of the desorption angle with the two methods-numerical treatment of the experimental TOF data and the curve fit with Eq. (2). The results are shown in Fig. 8. It is found that values obtained by the former method include fair uncertainties. This is due to small signal-to-noise ratios and to a limited time resolution in the experimental TOF spectra. At desorption angles between $45^{\circ}$ and $-45^{\circ}$, the angular dependence of $T_{\langle E\rangle}$ from the two methods is quite similar, excepting a constant difference. Maxima of $T_{\langle E\rangle}$ are observed at $\theta=$ $\pm 25^{\circ}$, where the desorption flux is maximized. $T_{\langle E\rangle}$ calculated from the fit function is always higher than that obtained by the numerical treatment. Its discrepancy is about 150-200 $\mathrm{K}$. No significant angular dependence is found in the SR value calculated from the two methods. Furthermore, the difference in the SR value between the two methods is less than 0.1 . The difference in $T_{\langle E\rangle}$ or SR values increases at desorption angles higher (or lower) than about $45^{\circ}$ (or $-45^{\circ}$ ), probably because of the decreasing signal-to-noise ratio of the TOF data.

In order to examine the fit function of Eq. (2), the Maxwellian distribution at $T=T_{\langle E\rangle}$ of Eq. (1) is also considered, where the value of $T_{\langle E\rangle}$ is obtained from the numerical treatment of the experimental TOF data. The resultant TOF curves are shown by the dashed curves in Figs. 5-7. They exhibit a slight peak shift towards longer flight time and a wider distribution in comparison with the TOF curves of Eq. (2). The latter curves fairly represent the peak profile in the experimental spectra. Thus one can say that the fit function in Eq. (2) form yields an upper limit in $T_{\langle E\rangle}$ and also a lower limit in SR.

To avoid ambiguity, in the following analysis we use the form of Eq. (2), where a fixed value of $\alpha=4.25 \times 10^{4} \mathrm{~cm} / \mathrm{s}$ $(500 \mathrm{~K})$ is used common for $\mathrm{P}_{2}-\mathrm{CO}_{2}, \mathrm{P}_{3}-\mathrm{CO}_{2}$, and $\mathrm{P}_{4}-\mathrm{CO}_{2}$ regardless of the desorption angle. The other parameter $v_{0}$ is
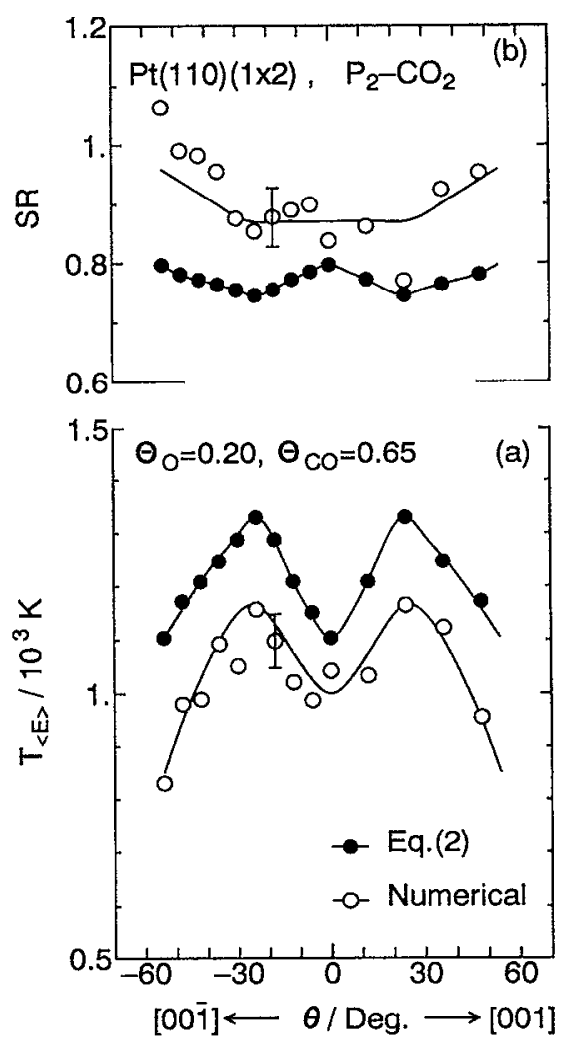

FIG. 8. Desorption angle dependence of (a) the translational temperature and (b) the normalized speed ratio of $\mathrm{P}_{2}-\mathrm{CO}_{2}$ in the [001] direction at $\Theta_{\mathrm{O}}=0.20$ and $\theta_{\mathrm{CO}}=0.65$. The black and white circles represent results obtained from the curve fit with Eq. (2) and from the numerical treatment of the experimental TOF data, respectively. Typical experimental errors are indicated by the vertical bars.

determined from the location of the peak in the experimental TOF spectrum. The translational temperature of $\mathrm{P}_{3}-\mathrm{CO}_{2}$ and $\mathrm{P}_{4}-\mathrm{CO}_{2}$ is plotted as a function of desorption angle as shown in Fig. 9. $T_{\langle E\rangle}$ of $\mathrm{P}_{3}-\mathrm{CO}_{2}$ at $\theta$ between $30^{\circ}$ and $-30^{\circ}$ is 1170 $\mathrm{K}$, independent of $\theta$. It is noticeably lower than the maximum of $T_{\langle E\rangle}$ for $\mathrm{P}_{2}-\mathrm{CO}_{2}(1330 \mathrm{~K}) . T_{\langle E\rangle}$ for $\mathrm{P}_{4}-\mathrm{CO}_{2}$ exhibits the maximum in the surface normal direction. It is close to the maximum $T_{\langle E\rangle}$ of $\mathrm{P}_{2}-\mathrm{CO}_{2}$.

TOF spectra of $\mathrm{P}_{2}-\mathrm{CO}_{2}, \mathrm{P}_{3}-\mathrm{CO}_{2}$, and $\mathrm{P}_{4}-\mathrm{CO}_{2}$ also were measured at a high $\mathrm{CO}$ coverage of $\theta_{\mathrm{CO}}=0.92$ and at typical desorption angles. The resultant $T_{\langle E\rangle}$ increases further around the surface normal direction as shown in Fig. 10. $T_{\langle E\rangle}$ of $\mathrm{P}_{2}-\mathrm{CO}_{2}$ still shows maxima at $\theta= \pm 25^{\circ}$. The values do not increase further at desorption angles higher (or lower) than $30^{\circ}$ (or $-30^{\circ}$ ). With increasing CO coverage, the translational temperature is enhanced only around the surface normal direction. This tendency of $T_{\langle E\rangle}$ correlates with an enhancement in the desorption flux around the surface normal direction at high $\mathrm{CO}$ coverages. This enhancement in the desorption flux indicates an increasing fraction of the normal-directional component. The above tendency of $T_{\langle E\rangle}$ strongly suggests that $T_{\langle E\rangle}$ of the normal-directional component is maximized at $\theta=0^{\circ}$. A more detailed analysis is given in the following. 

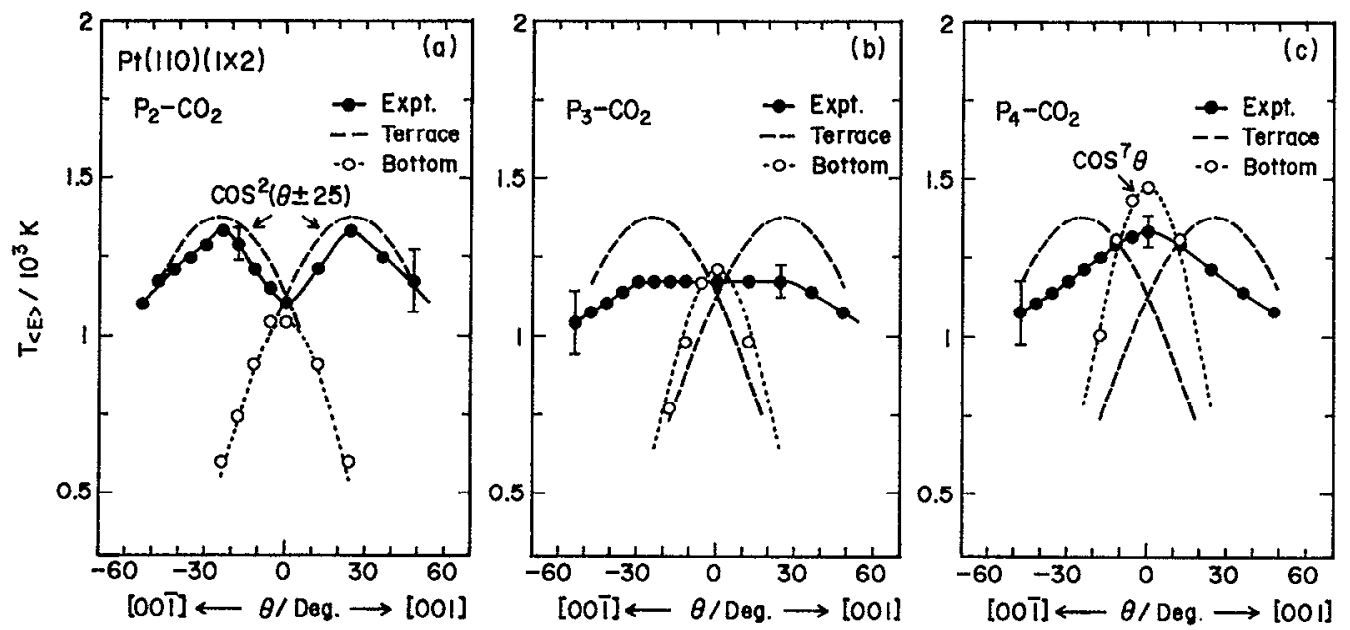

FIG. 9. Desorption angle dependence of the translational temperature of (a) $\mathrm{P}_{2}-\mathrm{CO}_{2}$; (b) $\mathrm{P}_{3}-\mathrm{CO}_{2}$; and (c) $\mathrm{P}_{4}-\mathrm{CO}_{2}$ in the $[001]$ direction at $\boldsymbol{\theta}_{\mathrm{O}}=0.20$ and $\theta_{\mathrm{CO}}=0.65$. The black circles represent experimental $T_{\langle E\rangle}$ obtained from the curve fit. The white circles indicate $T_{\langle E\rangle}$ of the normal-directional component calculated from the method described in the text. $T_{\langle E\rangle}$ of the two inclined components is shown by the dashed lines. Typical experimental errors are indicated by the vertical bars.

\section{E. Deconvolution of TOF spectra}

The previous section summarizes the deconvolution of an angular distribution curve in the [001] azimuth into three desorption components, i.e., two inclined components and normal-directional desorption. The observed TOF spectra are also contributed from these components. Their deconvolution yields the translational temperature of each desorption component. This is performed as follows.

First, TOF spectra for the two inclined components of $\mathrm{P}_{2}-\mathrm{CO}_{2}, \mathrm{P}_{3}-\mathrm{CO}_{2}$, and $\mathrm{P}_{4}-\mathrm{CO}_{2}$ are assumed to be identical to those for $\mathrm{P}_{2}-\mathrm{CO}_{2}$ at a low $\mathrm{CO}$ coverage since the latter TOF spectra consist only of inclined components. This assumption does not seem realistic since, in general, the angular distribution becomes sharp and $T_{\langle E\rangle}$ increases as the reactant coverage increases. ${ }^{3}$ Thus, the present treatment may provide an upper limit of $T_{\langle E\rangle}$ of the normal-directional component of $\mathrm{P}_{3}-\mathrm{CO}_{2}$ and $\mathrm{P}_{4}-\mathrm{CO}_{2}$, since the translational temperature of their inclined components is probably underestimated.

The desorption angle dependence of $T_{\langle E\rangle}$ was reported previously for $\mathrm{P}_{2}-\mathrm{CO}_{2}$ at $\Theta_{\mathrm{O}}=0.2$ and $\Theta_{\mathrm{CO}}=0.2$, where only the inclined components contribute to the desorption. ${ }^{5}$ In those treatments, $T_{\langle E\rangle}$ was estimated using Eq. (1). Now, $T_{\langle E\rangle}$ is recalculated by using Eq. (2) on the basis of TOF data obtained previously. The resultant $T_{\langle E\rangle}$ is shown by the dashed curves in Figs. 9 and 10. It is found to be described approximately by a simple form of $T_{\langle E\rangle}=T_{0} \cos ^{2}(\theta \pm 25)$, with $T_{0}=1370 \mathrm{~K}$. The TOF profile of the inclined component at each desorption angle is represented by Eq. (2), with the use of the $v_{0}$ value leading to this $T_{\langle E\rangle}$ value.
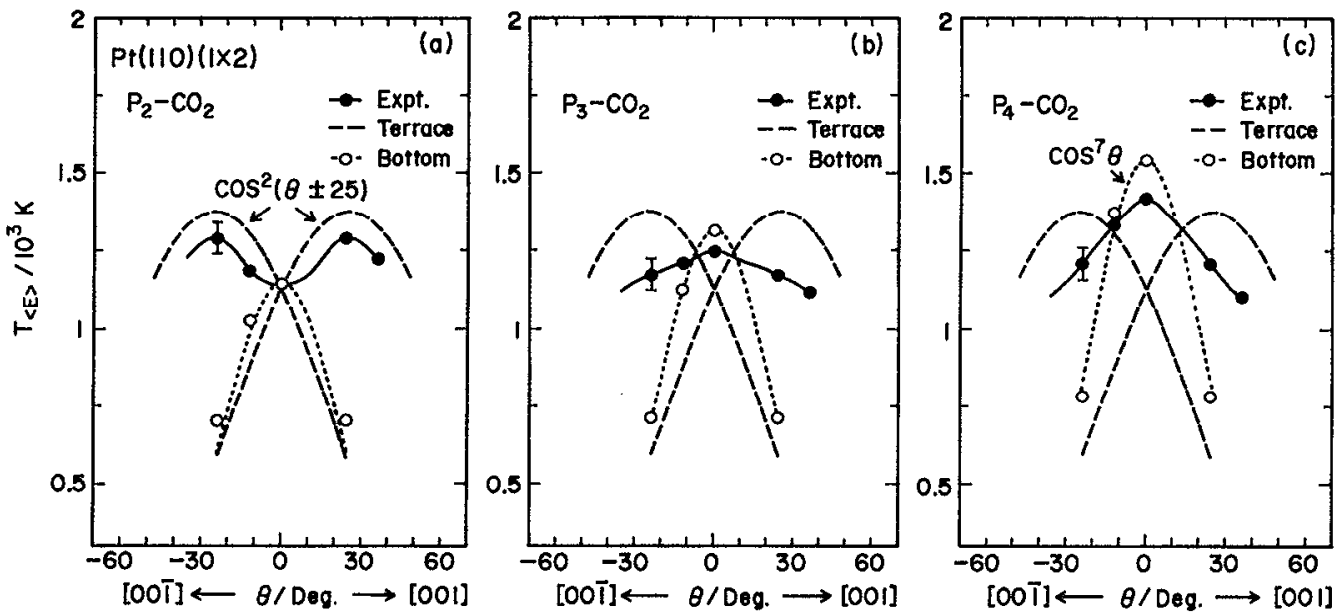

FIG. 10. Desorption angle dependence of the transnational temperature of (a) $\mathrm{P}_{2}-\mathrm{CO}_{2} ;$ (b) $\mathrm{P}_{3}-\mathrm{CO}_{2}$; and (c) $\mathrm{P}_{4}-\mathrm{CO}_{2}$ in the $[001]$ direction at $\Theta_{0}=0.20$ and $\Theta_{\mathrm{CO}}=0.92$. The other notations are given in Fig. 9. 
The total (composite) TOF curve consists of a superposition of each TOF component, which is calculated with its $v_{0}$ value describing inclined components or a normaldirectional component. The $v_{0}$ value of the normaldirectional component is now determined by numerically fitting $T_{\langle E\rangle}$, calculated from the composite TOF spectrum, with the experimental $T_{\langle E\rangle}$ obtained from the curve fit. The fraction of each TOF component is adjusted so as to reproduce the three components in the deconvoluted angular distribution in Figs. 2-4. Thus, TOF spectra can be deconvoluted successfully at desorption angles between $24^{\circ}$ and $-24^{\circ}$. The resultant $T_{\langle E\rangle}$ for each component is shown in Figs. 9 and 10. One should note the remarkable increase in the translational temperature of the normal directional component in the sequence of $\mathrm{P}_{2}-\mathrm{CO}_{2}<\mathrm{P}_{3}-\mathrm{CO}_{2}<\mathrm{P}_{4}-\mathrm{CO}_{2}$. This is consistent with the results on $\operatorname{Pd}(110)$, where the translational temperature increases with increasing coverages. Here, we must consider that $T_{\langle E\rangle}$ of normal component of $\mathrm{P}_{3}-\mathrm{CO}_{2}$ and $\mathrm{P}_{4}-\mathrm{CO}_{2}$ is overestimated. The value of $\mathrm{P}_{3}-\mathrm{CO}_{2}$ is certainly below that of the inclined component of $\mathrm{P}_{3}-\mathrm{CO}_{2}$, since it is overestimated. However, it is not clear that the value of $\mathrm{P}_{4}-\mathrm{CO}_{2}$ can exceed that of inclincd $\mathrm{P}_{4}-\mathrm{CO}_{2}$ because the former is overestimated and the latter is underestimated. No sharpening with increasing coverages is found in the angular distribution of the normal-directional component. This suggests remaining ambiguity in the deconvolution of the angular distributions.

\section{DISCUSSION}

\section{A. $\mathrm{CO}_{2}$ formation}

The coadsorption of $\mathrm{CO}$ and oxygen adatoms on platinum metals is characteristic of the separate domains of each species. ${ }^{23-25}$ This is caused by a significant repulsive force that operates between $\mathrm{CO}$ and oxygen. The oxygen or the $\mathrm{CO}$ domain is compressed into lattices with higher densities as their coverages increase. This compression starts first in local parts of the surface, where the activation energy for $\mathrm{CO}_{2}$ formation is reduced by the decrease in the heat of adsorption of the reactants. Hence, additional $\mathrm{CO}_{2}$ formation peaks appear at lower temperatures in the subsequent heating. This is the mechanism yielding several $\mathrm{CO}_{2}$ formation peaks in thermal desorption.

Several $\mathrm{CO}_{2}$ formation peaks are also observed on platinum surfaces with narrow terraces of a (111) structure. .,26,27 $^{5}$ However, only a single $\mathrm{CO}_{2}$ formation peak appears on a bulk $\mathrm{Pt}(111)$ plane over a wide range of $\mathrm{CO}$ coverages. ${ }^{28,29}$ On the other hand, oxygen lattices on $\operatorname{Pd}(111)$ are easily compressed by $\mathrm{CO}$, yielding three $\mathrm{CO}_{2}$ peaks. ${ }^{1,23}$ Here is a hint on the mechanism of domain compression. The heat of adsorption of $\mathrm{CO}$ seems to play an important role in this compression. $\mathrm{CO}$ is adsorbed on $\mathrm{Pd}(111)$ more strongly than on $\mathrm{Pt}(111)$.

$\mathrm{CO}$ adsorbs predominantly on step sites on platinum surfaces above $200 \mathrm{~K}$ even when the sites are first covered by oxygen. ${ }^{26}$ This becomes possible through the high adsorption heat of $\mathrm{CO}$ on step sites. ${ }^{30}$ Oxygen domains on the terrace are likely to be compressed by CO supplied from the step sites. A similar situation is expected on $\mathrm{Pt}(110)(1 \times 2)$. Oxy-

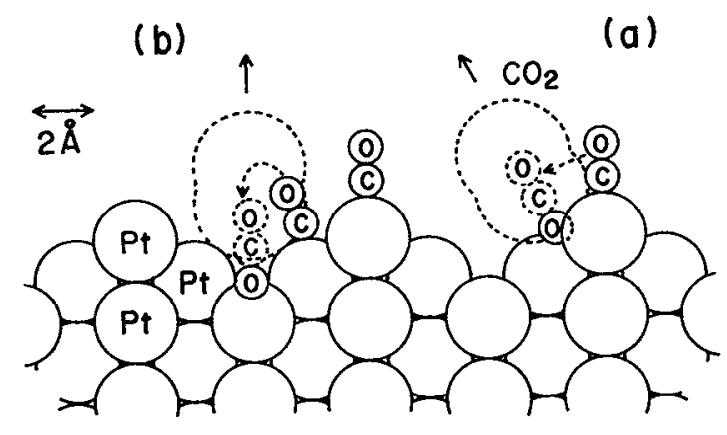

FIG. 11. The section of reaction sites (a) terrace site and (b) bottom site.

gen is likely to be first adsorbed on the bottom of the valley and populated onto the terrace with increasing coverage. ${ }^{31,32}$ On the other hand, $\mathrm{CO}$ is first adsorbed on top sites of [1 10$]$ atomic rows, and then supplied to the terrace with increasing coverage. This suggests that the reaction site is opened more closely to the bottom with increasing CO coverage.

\section{B. Location of reaction site}

The angular and velocity distributions of desorbing $\mathrm{CO}_{2}$ over a wide range of $\mathrm{CO}$ coverages indicate that the desorption consists of three components. Two of them are due to the desorption from the inclined terrace. Each component has a $\cos ^{12}(\theta \pm 25)$ dependence in the [001] azimuth and is sharply collimated at the desorption angles of $\pm 25^{\circ}$, in common with $\mathrm{P}_{2}-\mathrm{CO}_{2}, \mathrm{P}_{3}-\mathrm{CO}_{2}$ and $\mathrm{P}_{4}-\mathrm{CO}_{2}$. These $\mathrm{CO}_{2}$ molecules are produced on the inclined terraces as sketched in Fig. 11(a). This does not necessarily mean that oxygen and $\mathrm{CO}$ are adsorbed predominantly on the inclined terraces. Rather, at small coverages, oxygen is located on the bottom and $\mathrm{CO}$ is located on the top-atom row. Oxygen can be populated up to the terrace, since there are sites suitable for oxygen on the terrace as discussed below. $\mathrm{CO}_{2}$ formation is likely to proceed at each oxygen adsorption site, since $\mathrm{CO}$ molecules in the chemisorption state are much more mobile than $\mathrm{O}(a))^{33} \mathrm{CO}$ can react with oxygen when oxygen and CO move to the terrace.

Oxygen adatoms are located on the threefold hollow sites (without a host atom directly beneath the site) on a bulk $\mathrm{Pt}(111)$ plane. ${ }^{34}$ There are two such kinds of hollow sites on the present terraces of the $(1 \times 2)$ domain. The site between the first and the second layers is preferred for $\mathrm{CO}$ oxidation on the narrow terrace of $\operatorname{Ir}(110)(1 \times 2) .^{35}$ This terrace site would incline at $35.2^{\circ}$ if the surface metal atoms were located in the same position as that in the bulk crystal. There are large distortions in the first three layers, yielding about $\pm 30^{\circ}$ inclination. ${ }^{8,36,37}$ This angle is close to the position at which both the $\mathrm{CO}_{2}$ desorption flux and the mean translational energy are maximized. A significant difference, about $5^{\circ}$, is found between the $\mathrm{CO}_{2}$ collimation angle and the terrace angle. This may be explained by a smoothing effect of conduction electrons. ${ }^{5}$

The other desorption component is sharply collimated along the bulk surface normal. This component increases 
with increasing $\mathrm{CO}$ coverage. The angular distribution in the [001] azimuth is in a $\cos ^{15} \theta$ form, sharper than that in the [110] direction. ${ }^{4}$ This anisotropy is quite similar to those on $\operatorname{Pd}(110){ }^{2,3}$

There are two possible reaction sites for this normaldirectional component. First, a suitable reaction site may be provided on the bottom of the valley along the [110] direction on the $(1 \times 2)$ domain as shown in Fig. $11(\mathrm{~b}) .{ }^{38}$ Its local structure is quite similar to a site in the surface trough on $\operatorname{Pd}(110)$. This bottom site on the $(1 \times 2)$ domain works suitably for $\mathrm{P}_{4}-\mathrm{CO}_{2}$ formation, since this $\mathrm{CO}_{2}$ is produced below $200 \mathrm{~K}$, where the transformation of $(1 \times 2)$ into $(1 \times 1)$ structure is very slow even at high $\mathrm{CO}$ coverages. This site probably works for $\mathrm{P}_{3}-\mathrm{CO}_{2}$ as well. This assignment is consistent with the following consideration: As the $\mathrm{CO}$ coverage is increased, $\mathrm{CO}$ is also populated onto the terrace closer to the bottom of valley. Similar sites on $(1 \times 1)$ domains may contribute to $\mathrm{CO}_{2}$ formation, since the transformation occurs easily on the surface covered by $\mathrm{CO}$ and oxygen. ${ }^{4}$

On the other hand, the reaction site is no more clear for the normal-directional component of $\mathrm{P}_{2}-\mathrm{CO}_{2}$. The structural transformation into $(1 \times 1)$ is rapid above room temperature. The $(1 \times 1)$ domain can provide reaction sites suitable for the observed anisotropy in the angular distribution. No differentiation is possible for a bottom site between $(1 \times 2)$ domains and $(1 \times 1)$ domains. However, a bottom site on the $(1 \times 2)$ domain is preferable, since $\mathrm{CO}$ has a higher heat of adsorption on the $(1 \times 1)$ domain, yielding less reactivity.

\section{Translational temperature}

The TOF spectra are deconvoluted into the inclined component and the normal-directional component. As shown in Figs. 9 and 10 , the $T_{\langle E\rangle}$ value of the inclined component shows maxima of $1370 \mathrm{~K}$ at angles, where the desorption flux is maximized. It decreases with increasing shift from the collimation angle. The value for the normal-directional component shows the maximum in the surface normal direction and can be described as $T_{\langle E\rangle}=T_{0} \cos ^{7} \theta$, where the maximum value $T_{0}$ increases in the sequence of $\mathrm{P}_{2}-\mathrm{CO}_{2}<\mathrm{P}_{3}-\mathrm{CO}_{2}<\mathrm{P}_{4}-\mathrm{CO}_{2}$. The values of $T_{0}$ are compiled in Table I. They are somewhat lower than values observed in the reactive $\mathrm{CO}_{2}$ desorption on $\mathrm{Pd}(110){ }^{3} T_{\langle E\rangle}$ of the normaldirectional component varies sharply as a function of desorption angle. The dependence of $T_{\langle E\rangle}$ is quite different from that of the inclined component.

Moreover, the value of $T_{0}$ for the normal-directional component of $\mathrm{P}_{2}-\mathrm{CO}_{2}$ and $\mathrm{P}_{3}-\mathrm{CO}_{2}$ is lower than that of the inclined component. This indicates that $\mathrm{CO}_{2}$ produced on the terrace site is repulsed more strongly than that on the bottom site. The energy transfer into the translational motion on the terrace site occurs more effectively. Two possibilities may be considered. First, $\mathrm{CO}_{2}$ produced on the bottom site holds an internal energy higher than that on the terrace site. The other is that, in the desorption event, the energy transfer to the surface is more effective on the bottom site than the terrace site. A similar model has already been proposed on a stepped platinum surface. ${ }^{39}$ Internal energy distribution measurements are required to differentiate these mechanisms.
TABLE I. Dynamic parameters of desorbing product $\mathrm{CO}_{2}$ from $\mathrm{Pt}(110)(1$ $\times 2)$. TDS is started from (A) $\Theta_{\mathrm{Co}}=0.65$ and $(B) \Theta_{\mathrm{CO}}-0.92$.

\begin{tabular}{lcccc}
\hline \hline $\begin{array}{l}\text { Reaction } \\
\text { site }\end{array}$ & $\begin{array}{c}\mathrm{CO}_{2} \text { peak } \\
(\mathrm{K})\end{array}$ & $\begin{array}{c}\text { Angular distribution } \\
\theta \text { in }[001]\end{array}$ & $\begin{array}{c}\text { Translation temperature } \\
T_{(E)}(\mathrm{K})^{\mathrm{a}}\end{array}$ \\
\hline (A) & & & & \\
Terrace & & & & 1370 \\
& $\mathrm{P}_{2}$ & 300 & & \\
& $\mathrm{P}_{3}$ & 250 & $\cos ^{12}\left(\theta \pm 25^{\circ}\right)$ & 1040 \\
& $\mathrm{P}_{4}$ & 170 & & 1210 \\
Bottom & & & & 1470 \\
& $\mathrm{P}_{2}$ & 300 & $\cos ^{15} \theta$ & \\
& $\mathrm{P}_{3}$ & 250 & & \\
& $\mathrm{P}_{4}$ & 170 & & 1370 \\
(B) & & & & \\
Terrace & & & & 1140 \\
& $\mathrm{P}_{2}$ & 300 & $\cos ^{12}\left(\theta \pm 25^{\circ}\right)$ & 1310 \\
& $\mathrm{P}_{3}$ & 250 & & 1540 \\
\hline & $\mathrm{P}_{4}$ & 170 & & \\
\hline
\end{tabular}

${ }^{\mathrm{a}} T_{0}$ the maximum value of $T_{\langle E\rangle}=\langle E\rangle / 2 k$ is shown.

The $T_{0}$ value of the normal-directional component for $\mathrm{P}_{4}-\mathrm{CO}_{2}$ was estimated to be higher than that of the inclined component. This is not confirmed as discussed in Sec. III E. The increasing $T_{0}$ of the normal-directional component in the sequence of $\mathrm{P}_{2}-\mathrm{CO}_{2}, \mathrm{P}_{3}-\mathrm{CO}_{2}$, and $\mathrm{P}_{4}-\mathrm{CO}_{2}$ is consistent with the observation on $\operatorname{Pd}(110){ }^{3}$

\section{SUMMARY}

The angular and velocity distributions of desorbing $\mathrm{CO}_{2}$ produced on a platinum $(110)(1 \times 2)$ surface were studied over a wide range of $\mathrm{CO}$ and oxygen coverages by means of angle-resolved thermal desorption combined with a crosscorrelation time-of-fight technique. Results are summarized as follows.

(1) Heating the coadsorption layer of $\mathrm{CO}$ and oxygen yields four $\mathrm{CO}_{2}$ formation peaks in the range of $170-400 \mathrm{~K}$.

(2) The angular distribution of $\mathrm{CO}_{2}$ perpendicular to the terrace consists of three desorption components. Two of them show the desorption collimated along the inclined terrace normal. These are due to the reaction on the terrace. The other, sharply collimated along the bulk surface normal, is mostly produced on the bottom of the trough.

(3) For $\mathrm{P}_{2}-\mathrm{CO}_{2}$ and $\mathrm{P}_{3}-\mathrm{CO}_{2}$, the maximum translational temperature of the normal-directional component is lower than that of the inclined components. For $\mathrm{P}_{4}-\mathrm{CO}_{2}$, the maximum translational temperature of the former is close to that of the latler.

\section{ACKNOWLEDGMENT}

This work was supported in part by a grant in Aid for Scientific Research from the Ministry of Education no. 05225202. 
${ }^{1}$ T. Matsushima and H. Asada, J. Chem. Phys. 85, 1658 (1986).

${ }^{2}$ T. Matsushima, J. Chem. Phys. 91, 5722 (1989).

${ }^{3}$ T. Matsushima, K. Shobatake, Y. Ohno, and K. Tabayashi, J. Chem. Phys. 97, 2783 (1992).

${ }^{4}$ T. Matsushima, J. Chem. Phys. 93, 1464 (1990).

${ }^{5}$ T. Matsushima, K. Shobatake, and Y. Ohno, Surf. Sci. 283, 101 (1993).

${ }^{6}$ T. Matsushima, Y. Ohno, and K. Nagai, J. Chem. Phys. 94, 704 (1991).

${ }^{7}$ T. Matsushima, Y. Ohno, and A. Rar, Surf. Sci. 293, 145 (1993).

${ }^{8}$ E. C. Sowa, M. A. Van Hove, and D. L. Adams, Surf. Sci. 199, 174 (1988).

${ }^{9}$ T. Gritsch, D. Coulman, R. J. Behm, and G. Ertl, Appl. Phys. A 49, 403 (1989); T. Gritsch, D. Coulman, R. J. Behm, and G. ErtI, Phys. Rev. Lett. 63, 1086 (1989).

${ }^{10}$ E. Vlieg, I. K. Robinson, and K. Kern, Surf. Sci. 233, 248 (1990).

${ }^{11}$ T. Gritsch, D. Coulman, R. J. Behm, and G. Ertl, Surf. Sci. 257, 297 (1991).

${ }^{12}$ S. Ferrer and H. P. Bonzel, Surf. Sci. 119, 234 (1982).

${ }^{13}$ K. Heinz, A. Barthel, L. Hammer, and K. Müller, Surf. Sci. 191, 174 (1987).

${ }^{14}$ J. K. Zuo, Y. L. He, G. C. Wang, and T. E. Felter, J. Vac. Sci. Technol. A 8, 2474 (1990).

${ }^{15}$ G. Comsa, R. David, and B. J. Schumacher, Rev. Sci. Instrum. 52, 789 (1981).

${ }^{16}$ T. E. Jackman, J. A. Davies, D. P. Jackson, W. N. Unertl, and P. R. Norton, Surf. Sci. 120, 389 (1982).

${ }^{17}$ Y. Ohno and T. Matsushima, Surf. Sci. 241, 47 (1991).

${ }^{18}$ N. Freyer, M. Kiskinova, G. Pirug, and H. P. Bonzel, Surf. Sci. 166, 206 (1986).

${ }^{19}$ T. E. Kenney, A. E. Dabiri, and R. E. Stickney, Research Laboratory of Electronics, MIT Quarterly Progress Report No. 102, July 1971, p. 39.
${ }^{20}$ T. Matsushima, Y. Ohno, and J. Murakami, Surf. Sci. 287/288, 192 (1993).

${ }^{2 !}$ C. A. Becker, J. P. Cowin, L. Wharton, and D. J. Auerbach, J. Chem. Phys. 67, 3394 (1977).

${ }^{22}$ L. S. Brown and S. J. Sibener, J. Chem. Phys. 90, 2807 (1989).

${ }^{23} \mathrm{H}$. Conrad, G. Eitl, and J. Küppers, Surf, Sci. 76, 323 (1978).

${ }^{24}$ E. M. Stuve, R. J. Madix, and C. R. Brundle, Surf. Sci. 146, 155 (1984).

${ }^{25}$ Y. Ohno, T. Matsushima, K. Shobatake, and H. Nozoye, Surf. Sci. 273, 291 (1992).

${ }^{26}$ A. Szabo, M. A. Henderson, and J. T. Yates, Jr., J. Chem. Phys. 96, 6191 (1992).

${ }^{27}$ J. L. Gland, M. R. McClellan, and F. R. McFeely, J. Chem. Phys. 79, 6349 (1983).

${ }^{28}$ T. Matsushima, Surf. Sci. 127, 403 (1983).

${ }^{29}$ J. L. Gland and E. B. Kollin, Surf. Sci. 151, 260 (1985).

${ }^{30}$ M. A. Henderson, A. Szabo, and J. T. Yates, Jr., J. Chem. Phys. 91, 7245 (1989): 91, 7255 (1989).

${ }^{31}$ Y. Ohno, T. Matsushima, S. Tanaka, E. Yagasaki, and M. Kamada, Surf. Sci. 275, 281 (1992).

32 J. Schmidt, Ch. Stuhlmann, and H. Ibach, Surf. Sci. 284, 121 (1993).

${ }^{33}$ J. E. Reutt-Robey, D. J. Doren, Y. J. Chabal, and S. B. Christman, Phys. Rev. Lett. 61, 2778 (1988).

${ }^{34}$ K. Mortensen, C. Klink, F. Jensen, F. Besenbacher, and I. Stensgaard, Surf. Sci. 220, L701 (1989).

${ }^{35}$ Y. Ohno, T. Matsushima, and H. Miki, Surf. Sci. 281, 234 (1993).

${ }^{36}$ S. Holmberg, H. C. Poon, Y. Jugnet, G. Grenet, and T. M. Duc, Surf. Sci. Lett. 254, L475 (1991).

${ }^{37}$ F. Masson and J. W. Rabalais, Surf. Sci. 253, 245 (1991).

${ }^{38}$ R. Ducros and R. P. Merrill, Surf. Sci. 55, 227 (1976).

${ }^{39}$ J. Segner, C. T. Campbell, G. Doyen, and G. Ertl, Surf. Sci. 138, 505 (1984). 
The Journal of Chemical Physics is copyrighted by the American Institute of Physics (AIP). Redistribution of journal material is subject to the AIP online journal license and/or AIP copyright. For more information, see http:/ojps.aip.org/jcpo/jcpcr/jsp Copyright of Journal of Chemical Physics is the property of American Institute of Physics and its content may not be copied or emailed to multiple sites or posted to a listserv without the copyright holder's express written permission. However, users may print, download, or email articles for individual use. 